REDES- Revista hispana para el análisis de redes sociales

Vol. 7,\#4, Oct./Nov. 2004.

http://revista-redes.rediris.es

\title{
Los espacios sociales de la transnacionalidad. Una tipología de la integración relacional de los migrantes $^{[1]}$
}

\author{
Ainhoa de Federico de la Rúa ${ }^{[2]}$, Universidad de Lille, Francia
}

\begin{abstract}
Following the classical community studies, Ferrand (2002) reminds the importance of "local communities" as a meso social intermediate agency for social regulation between the macro social level of national regulation and the micro social level of interpersonal regulation. An important caracteristic of local communities is its level of delocaliztion or its degrée of openness: social networks go beyond borders, they can be dual, simoultaneously local and non-local. The duality local/non-local can be expressed in structural terms through the concep of "bridge". A tie can be called a bridge when it links two different and unrelated sub-networks. Based on the idea that the efficiendy of bridges depends on the type of cliques that it connects (Lin 2001), it is possible to define different types of micro-structures. The distribution of these micro-structures are herzatz * sucedaneous * indicators or approximations for the different meso structures of relational systems as combinations of local and non local networks. These concepts are particularly interesting to caracterize the modalities of relational integration of migrants, typical local and non-local actors. We propose a triple distinction of their ties: local ties (with people coming from the hosting society), national ties (with people having their same nationality) and transnational ties (with people having other origins). The identification of the elementary structures of relational integration allows to caracterize simultaneously the modalities of integration of actors with different profiles of integration and, by looking at the combination of profiles of integration in a given social space, the caracterization of different types of transnational communities.
\end{abstract}

Key words: Transnational communities, meso structures, personal networks, typologies, globalization.

\section{RESUMEN}

Siguiendo los Community Studies, Ferrand (2002) recuerda la importancia de la "comunidad local" como agencia de regulación social intermediaria, meso-social, entre el nivel macro social de regulación nacional y el nivel micro social interpersonal. Una característica importante de las "comunidades locales" es su nivel de des-localización o de apertura: las redes sociales atraviesan las fronteras, pueden ser "duales", simultáneamente locales y no locales. La dualidad local / no local puede ser formulada en términos estructurales con el concepto de puente: una relación cuyos extremos pertenecen a dos sub-redes diferentes y no relacionadas. Apoyándose en la idea de que la eficiencia de los "puentes" depende del tipo de cliques que conectan (Lin 2001), es posible definir tipos variados de micro-estructuras, cuyas distribuciones son indicadores sucedáneos 0 aproximaciones de las diferentes meso-estructuras de sistemas relacionales como combinaciones de redes "locales" y "no locales". Estas nociones son particularmente 
interesantes para caracterizar los modos de integración relacional de los migrantes, actores simultáneamente locales y no locales por excelencia. Proponemos una triple distinción de sus lazos: locales (personas de la sociedad de acogida), nacionales (personas de su mismo origen) y transnacionales (personas de otras procedencias). La identificación de las estructuras elementales de la integración relacional permite simultáneamente caracterizar las modalidades de integración de los actores (perfiles de integración aislado, nacional, apátrida, tránsfugo, extranjero, bi-local, fugado o cosmopolita) y, mediante la combinatoria hallada en un espacio social definido, la caracterización de los distintos tipos de comunidades transnacionales, espacios sociales de la transnacionalidad.

\section{I ntroducción}

El hecho de que vivimos en un mundo cada vez más globalizado es un tema recurrente tanto en los análisis sociales como en los medios de comunicación. Para muchos la globalización significa que las fronteras nacionales, culturales y sociales, antaño claras y seguras, son traspasadas por números crecientes de flujos cruzados de personas, información, imágenes, bienes y capitales. Las comunidades, formalmente fijadas en localidades, se vuelven cada vez más des-localizadas, lanzadas al cyberespacio y/o ligadas a redes de gran alcance que se extienden entre continentes. Por lo tanto, la globalización es para un número mayor de grupos y personas un factor de importancia creciente en sus vidas y experiencias mientras que tratan de adaptarse a la fragmentación, de reconstruirse constantemente, a la vez que manejan identidades personales múltiples y de gestionar su implicación en redes transnacionales. Como consecuencia, se está construyendo rápidamente una esfera que se podría llamar global mediante el funcionamiento de diversas redes entrelazadas cada vez más densas (Kennedy 2001). Según Albrow (1990) la globalización se refiere a "todos los procesos mediante los cuales las personas del mundo son incorporadas a una única sociedad, una sociedad global". A pesar de que algunos siguen dudando sobre la importancia de la globalización, la mayoría de los sociólogos admiten que el mundo está cambiando rápidamente y de forma radical, Giddens (1998) por ejemplo afirma que la globalización se encuentra actualmente por todas partes. La compresión del tiempo y del espacio gracias a las innovaciones tecnológicas y cambios sociales conduce a cada vez más gente diferente a entrar en contacto entre sí mediante, por ejemplo la migración y el turismo. El 
desarrollo de conexiones y redes entre organizaciones y actores transnacionales de poder creciente promueven interdependencias aún mayores (Pourmehdi 2001).

La globalización, por lo tanto, se acompaña del incremento de la circulación de las personas a través de las fronteras - migraciones más numerosas y diversificadas- y de un cambio en la naturaleza de las comunidades de migrantes y de sus relaciones con las sociedades de que proceden y con aquellas que los acogen. Las comunidades de la diáspora, a pesar de su tendencia a la migración, se están liberando de las presiones asimilacionistas anteriores (p.e. los turcos en Holanda, ver Amersfoort y Doomernik, 1999). Ya no podemos ver las comunidades de inmigrantes como conjuntos de personas que abandonan su país, dado que muchos mantienen contactos frecuentes a través de redes con múltiples conexiones que atraviesan las fronteras y las identidades nacionales. Los países de origen y de residencia están conectados por medios de transporte, intercambios culturales y comunicaciones electrónicas.

Así pues, según sus pertenencias a redes más o menos interconectadas y deslocalizadas, las personas mantienen identidades múltiples (Matthews: 1999). La desterritorialización y la separación de la comunidad y la identidad del espacio físico no niegan la localidad, pero la relativizan y la descentran.

Los párrafos que preceden presentan las visiones de algunos estudiosos de la globalización. Éstos apuntan sin duda de forma certera algunas de las transformaciones a que se ven expuestas las sociedades contemporáneas, en particular, la creciente diferenciación y complejidad de las comunidades transnacionales. Se podría decir que en los años sesenta las diferentes comunidades de inmigrantes podían describirse en términos de la intersección entre la cultura de las sociedades de origen, sus modos de vida y tradiciones, con los sistemas legales y la cultura de las sociedades de acogida (por ejemplo la integración diferente de los españoles vs. la de los magrebíes en Francia, pero también estas mismas comunidades en Francia vs. las mismas en Holanda). Sin embargo, hoy en día es cada vez más importante tener en cuenta algo más - para hablar de las diferencias 
actuales entre p.e. las comunidades de japoneses en los países de América Latina y las de pakistaníes en Gran Bretaña no es suficiente la referencia a las sociedades de origen y a las de acogida - es imprescindible centrarse en las comunidades transnacionales propiamente dichas. Para ello el concepto teórico clave, tal y como ya apuntan los estudiosos de la globalización, es el de las redes sociales. Sin embargo en aras de una verdadera comprensión, es también necesario trascender el lenguaje meramente metafórico del que a veces dichos estudiosos abusan y favorecer una perspectiva teórica que permita una aproximación analítica operacionalizable metodológicamente.

El propósito del presente artículo es hacer una modesta contribución al estudio y la comprensión de las comunidades transnacionales contemporáneas proponiendo una tipología de los espacios sociales de la transnacionalidad basándose en las diferentes características de las redes sociales que las componen. Para construir nuestra aproximación, que se apoya explícitamente en la de Ferrand (1997, 1999 y 2002), será necesario en primer lugar hacer referencia a un cierto número de conceptos, algunos de ellos ya clásicos, en el análisis estructural.

\section{Las estructuras meso-sociales. El punto de vista de las comunidades "locales".}

Siguiendo a Ferrand (2002), podemos decir que entre el nivel micro social y el nivel macro social existe una agencia clave de regulación intermedia meso social. Si el nivel macro está definido por la regulación nacional, estatal o del mercado y el nivel micro por la regulación interpersonal, una agencia de regulación intermediaria de mayor importancia ha sido definida como "comunidad local". Esta perspectiva es heredera de la tradición clásica de los estudios de comunidades (community studies, Barnes 1954, Wellman 1988 y Fischer 1984) aunque su metodología ha sido modernizada (Ferrand 2002). El postulado básico de este paradigma es que los sistemas locales existen y que debemos descubrir sus modelos formales y funcionales. Tomar éste postulado como punto de partida permitirá abordar de forma explícita la cuestión apuntada por los teóricos de la globalización de la desterritorialización y la relativización de la localidad. En efecto, tal postulado no puede ser asumido para todos los componentes de las 
localidades. Los datos empíricos muestran que las personas mantienen redes de relaciones que incluyen mayor o menor número y proporción de personas viviendo "en la misma localidad" al igual que "en otra parte". Por lo tanto, aparte de las dimensiones organizacionales (organizaciones locales, clubes, tiendas...) e institucionales (poder local, partidos...) propiamente locales, existe el llamado "tercer campo" (Barnes 1954) de redes ilimitadas de relaciones sociales con parientes, amistades, conocidos y todo tipo de contactos que pueden encontrarse en la propia localidad o fuera de ésta.

Así pues, es posible definir algunas propiedades estructurales pertinentes de los sistemas de relaciones interpersonales privadas: uno es el grado de "cerrado local" (closure). Dado que las redes sociales no tienen por qué limitarse a ninguna frontera estas pueden ser duales es decir, simultáneamente locales y no locales. La dualidad "local" / "no local" puede ser formulada en términos estructurales gracias el concepto de puente. Un puente es una relación cuyos extremos pertenecen a dos sub-redes diferentes y no relacionadas. Apoyándose en la idea de que la eficiencia de los "puentes" reside en el tipo de cliques que conectan (Lin 2001), es posible definir tipos variados de micro-estructuras, cuyas distribuciones son indicadores sucedáneos o aproximaciones de las diferentes meso estructuras de sistemas relacionales como combinaciones de redes "locales" y "no locales". A partir de esta idea, se puede definir un sistema relacional con sus propiedades estructurales características y sus efectos al nivel meso. Basándose en la teoría del capital social, es posible dar cuenta de las variaciones de las propiedades estructurales de las redes sociales que atraviesan diferentes localidades. Siguiendo esta idea, Ferrand propone una - sencilla pero muy útil - clasificación de los actores según las proporciones de los lazos locales y no locales en sus redes personales privadas: a) actores limitados localmente, que sólo disponen de relaciones en la comunidad local; b) difusores con una integración "dual" local y no local con predominio de lazos locales; c) cosmopolitas con una integración "dual" con relaciones locales y no locales, pero esta vez con predominio de relaciones no locales; d) no locales o actores que solamente tienen relaciones exteriores a la localidad; e) aislados que no tienen ninguna relación. 
Esta formulación no cambia la suposición básica que se refiere a la consistencia del sistema local. Una característica de particular interés de las “comunidades locales" es por lo tanto su nivel de des-localización o de apertura. Esta misma podrá ser caracterizada a partir de las distribuciones de actores aislados, limitados, difusores, cosmopolitas y no locales.

Tabla 1. Distribución de actores según redes personales en cuatro localidades ficticias.

\begin{tabular}{|c|c|c|c|c|}
\hline Micro estructuras & Localidad A & Localidad B & Localidad C & Localidad D \\
\hline Aislados & $20 \%$ & $20 \%$ & $20 \%$ & $60 \%$ \\
\hline Limitados & $40 \%$ & $40 \%$ & $5 \%$ & $10 \%$ \\
\hline Difusores & $5 \%$ & $35 \%$ & $10 \%$ & $10 \%$ \\
\hline Cosmopolitas & $5 \%$ & $5 \%$ & $30 \%$ & $10 \%$ \\
\hline No Locales & $35 \%$ & $5 \%$ & $35 \%$ & $10 \%$ \\
\hline Total & $100 \%$ & $100 \%$ & $100 \%$ & $100 \%$ \\
\hline
\end{tabular}

La cuestión clave es que estas distribuciones dan información no sólo sobre las "localidades" en sí mismas, sino sobre las maneras en que unidades locales efectúan la intersección con sistemas relacionales no locales ilimitados (Ferrand 2002, p8).

A partir de estas distribuciones se puede, a su vez, establecer una tipología sobre las formas de dualidad de las comunidades locales.

Tabla 2. Formas de dualidad de las comunidades locales.

\begin{tabular}{|c|c|c|}
\hline $\begin{array}{c}\text { Formas de dualidad } \\
\text { Meso estructuras }\end{array}$ & Conectividad externa fuerte & Conectividad externa débil \\
\hline Conectividad interna fuerte & Localidad A & Localidad B \\
\hline Conectividad interna débil & Localidad C & Localidad D \\
\hline
\end{tabular}

Esta imagen está definida a partir de un "punto de vista" geográfico local, pero tiene en cuenta simultáneamente lo que es local y no local en las localidades. Esta aproximación permite definir las formas de dualidad como un tipo de propiedades estructurales de las localidades.

La aproximación de Ferrand tiene la virtud de tener una interesante capacidad teórica apoyada en una metodología relativamente sencilla. Para caracterizar las formas de dualidad de las localidades se utiliza como indicador la distribución de micro-estructuras en las redes personales de los residentes, lo que permite la investigación empírica mediante encuestas 
aleatorias de las redes personales de los residentes. La información sobre las redes personales permite por lo tanto una doble caracterización: realizar una tipología de la integración relacional de los residentes y una tipología de las formas de dualidad de las localidades.

Sin embargo, apunta el propio Ferrand "una localidad no es per se una realidad de nivel meso. Las localidades son elementos de un sistema meso mayor en que las unidades locales y no locales se encuentran en intersección. La teoría debe tratar tanto con la organización local de las relaciones como con la red ilimitada, compleja y difícil de rastrear de relaciones no locales.

\section{Las estructuras meso sociales. El punto de vista de las comunidades "transnacionales"}

Las ideas apuntadas por Ferrand son particularmente interesantes para caracterizar los modos de integración relacional de los migrantes, ya que los migrantes son precisamente actores simultáneamente locales y no locales por excelencia, y sus modalidades de integración en diferentes sistemas relacionales meso reflejan sus relaciones más amplias a las sociedades de origen y de acogida.

Para proponer una aplicación más apropiada al estudio de las comunidades de migrantes o de las comunidades transnacionales sugerimos realizar dos modificaciones respecto a la aproximación propuesta por Ferrand. La primera es cambiar el punto de vista de la "comunidad local" por un punto de vista de la propia "comunidad transnacional" que nos interese estudiar, el punto de partida en este caso es, aunque no estrictamente reticular, si más próximo a la propia realidad de nivel meso. La segunda, consecuencia de la primera, es modificar la caracterización clásica dual del lazo como "local" o "no local" a una de naturaleza levemente diferente, para luego extenderla de forma más significativa al caso específico de las comunidades transnacionales. Examinemos la cuestión paso a paso: si el punto de vista adoptado es el de una comunidad de inmigrantes " $\mathrm{A}$ ", la primera caracterización de las relaciones que sustituye a las relaciones "locales"|"no locales" sería las relaciones con personas "pertenecientes a la comunidad de 
inmigrantes A" y relaciones con "personas que no pertenecen a esta categoría de inmigrantes".

Si aplicamos las ideas de Ferrand (2002) a una distinción, por ejemplo, en términos de relaciones de personas pertenecientes a una comunidad inmigrada con a) personas pertenecientes a esta comunidad (personas del mismo origen) y b) personas del país de acogida, en cierta medida, a partir de las categorías de integración relacional podríamos reconocer las modalidades de adaptación a una nueva cultura y entorno definidas por Berry.

Para Berry (1986 en Recchi y Nebe 2003) la adaptación es un proceso bidireccional. Antes de sus trabajos, los modelos dominantes eran modelos de aculturación uni-direccionales (Gordon 1964, Redfield et al. 1936) en que la adaptación era comprendida como un proceso de alejamiento de la cultura del país de origen para incorporarse psicológica y socialmente a la cultura del país de acogida. Berry propone que la adaptación a una nueva cultura y a una nueva sociedad implica de forma simultánea la redefinición de su relación a la cultura de acogida así como a la cultura de origen. Propone por lo tanto que la adaptación puede ir de lo que llama la integración, en que los individuos mantienen relaciones fuertes con la sociedad de acogida y de origen, a la marginalización, en que no se está ligado a ninguna de las dos, pasando por relaciones asimétricas, ya sea con una relación más fuerte con la sociedad de origen (separación) ya sea con la de acogida (asimilación).

Estas tipologías son útiles para conceptualizar ciertas formas de integración cultural (Berry 1986) y relacional (Ferrand 2002). Sin embargo, existen argumentos teóricos para pensar que individuos en la posición sociológica de extranjeros, tal y como la definen Simmel (1908) y Schutz (1954), sean proclives a desarrollar relaciones, un modo de vida y normas propiamente transnacionales particulares a las comunidades de expatriados y que pueden no ser ni los de la sociedad de origen ni los de la sociedad de acogida. En las localidades de acogida pueden emerger comunidades cosmopolitas de migrantes de distintos orígenes. De un punto de vista cultural o normativo se pueden producir "hibridaciones" (Kohli 2000), "interculturaciones" diversas, incluso los actores pueden desarrollar 
repertorios de roles múltiples a utilizar según las circunstancias (Wagner 1998). Distintos autores han descrito este fenómeno en comunidades transnacionales en Europa, p.e. los círculos de burócratas europeos de Bruselas (Abéles 1998), los inmigrantes de clases altas en París (Wagner 1998), comparaciones entre inmigrantes de clases altas y clases populares en París, Londres, Bruselas y Ámsterdam (Favell 1999).

¿Cómo considerar entonces las relaciones con los otros inmigrantes que no pertenecen a la misma comunidad original? De un punto de vista estrictamente geográfico son relaciones locales, puesto que los asociados se encuentran en la misma localidad, en el mismo espacio que ego. Sin embargo, de un punto de vista simbólico y cultural estas relaciones no son en absoluto "locales" y abren las puertas hacia otros universos, otros lugares, no obstante son vividas en un contexto geográfico común a todos los migrantes. Por lo tanto, pensamos que las relaciones con personas de idéntico origen, las relaciones con migrantes de origen diferente y las relaciones con personas locales en el sentido de pertenecientes a la sociedad de acogida traducen distintos modos de integración y relaciones diferentes a la sociedad de acogida. Así mismo son los lugares de intersección de distintas meso-estructuras y constituyen puentes de naturaleza diferentes.

Tabla 3. Combinatoria de los tipos de relaciones nacionales, migrantes, locales.

\begin{tabular}{|c|l|c|c|}
\hline $\begin{array}{c}\text { Combinatoria: } \\
\text { nacional/transnacionalidad }\end{array}$ & \multicolumn{1}{|c|}{ Descripción } & Perfil & Puente \\
\hline$(0,0,0)$ & Ninguna relación & Aislado & No \\
\hline$(1,0,0)$ & Sólo lazos nacionales & Nacional & No \\
\hline$(0,1,0)$ & Sólo lazos transnacionales & Apátrida & No \\
\hline$(0,0,1)$ & Sólo lazos locales & Tránsfugo & Extranjero \\
\hline$(1,1,0)$ & Lazos nacionales y & Bi-local & 1: origen-local \\
\hline \hline$(1,0,1)$ & transnacionales & Fugado & 1: transnacional-local \\
\hline$(0,1,1)$ & Lazos nacionales y locales & Cazos transnacionales y & $\begin{array}{l}\text { 3: origen-transnacional, } \\
\text { origen-local y } \\
\text { transnacional-local }\end{array}$ \\
\hline \hline$(1,1,1)$ & $\begin{array}{l}\text { Lazos nacionales, } \\
\text { transnacionales y locales }\end{array}$ & & \\
\hline
\end{tabular}


Para simplificar ${ }^{[3]}$ en adelante los llamaremos relaciones "nacionales" aquellas establecidas con personas del mismo origen, "transnacionales" cuando se trate de relaciones con personas de origen diferente ${ }^{[4]}$ y "locales" cuando se trate de lazos con personas de la sociedad de acogida.

A partir de la definición de estos tres tipos de relaciones es posible elaborar la combinatoria de éstas que podemos hallar en las redes personales de los migrantes. Según esta combinatoria las redes personales constituirán micro-estructuras puente entre meso-estructuras relacionales más amplias o no. Los puentes que pueden ser constituidos son los siguientes: a) puente sociedad de origen-sociedad de acogida, b) puente sociedad de origencomunidad transnacional, c) puente comunidad transnacional-sociedad de acogida, d) puente sociedad de origen-comunidad transnacional- sociedad de acogida, e) ausencia de puente.

Veamos a continuación la combinatoria de las relaciones, los perfiles de integración que denotan y los tipos de puentes que establecen.

La primera categoría llamada aquí aislados corresponde a alguien que no tiene ninguna relación. Esta categoría es poco probable, pero el hecho de mencionarla explícitamente permite afirmar que se trata de los únicos individuos que se pueda verdaderamente considerar no integrados. Todas las otras categorías presentan modalidades de integración relacionales diferentes cuya forma varía.

Siguen tres categorías "puras" llamadas así porque solamente incluyen una categoría de relación en la red personal: o bien relaciones nacionales, o sólo transnacionales, o únicamente locales. En ninguno de estos tres casos la red personal de los individuos constituye una micro-estructura que establece puentes entre meso-estructuras relacionales diferentes ligando la sociedad local, de origen y la comunidad transnacional.

No es arriesgado suponer que la más probable de estas categorías sea la del nacional, alguien que sólo tiene relaciones con personas de su propio país de origen. Una ilustración histórica apropiada de este tipo sería por ejemplo la de los colonos Británicos en la India que mantenían una sociabilidad exclusivamente británica y que insistían en tomar su «five o'clock tea » bajo cualquier circunstancia. La figura de este tipo de migrante 
es la de un individuo cuyo desplazamiento se ha limitado a un mero desplazamiento geográfico y lo que minimiza los efectos de éste en su modo de vida, normas y tipo de sociabilidad.

El llamado apátrida es un individuo con lazos exclusivamente en la comunidad transnacional. Esta persona parece corresponder a un tipo más curioso o más adaptable, más capaz de aprender o de llegar a compromisos sobre las normas y de tener la paciencia de crear otras nuevas a partir de puntos de partida diferentes. En cierta medida, el apátrida puro es un individuo que tiene más interés o más capacidad para crear lazos transnacionales; al mismo tiempo se trata de alguien que, o no puede crear lazos con personas de su nacionalidad (por ejemplo si no están presentes en el entorno) o las evita por los motivos que fuese (p.e. como estrategia de distinción). Al mismo tiempo parece encarnar la persona desterritorializada por excelencia: sin estar ligada por medio de relaciones con su país de origen, tampoco lo está con el país que la acoge. El apátrida vive en un mundo únicamente "transnacional", no sólo más allá de las fronteras, sino siendo incapaz de echar raíces en algún lado. Esta imagen puede corresponder con tipos de migrantes de los que nos habla Favell (1999) que desarrollan modos de vida propiamente "transnacionales". Estamos aquí frente a un caso particular puesto que aunque de un punto de vista estrictamente estructural el apátrida no constituye un puente entre comunidades, ya que éste está aislado de la comunidad local y de la de origen, el hecho de estar en contacto con personas de otros orígenes diversos puede contribuir a los procesos de hibridación cultural ${ }^{[5]}$.

La última posibilidad corresponde al tránsfugo, es decir, alguien que rehúsa establecer relaciones salvo con personas de la sociedad de acogida. Belorgey (1989) identifica esta figura en la literatura romántica del XIX: el viajero que trata de enraizarse en la sociedad de destino, a menudo exótica, que se asimila o se acultura totalmente de forma voluntaria a un nuevo entorno. El tránsfugo evita las relaciones con aquellos que más se le asemejan ya sea aquellos de iguales orígenes $u$ otros extranjeros $\mathrm{y}$, por el contrario, mantiene relaciones preferentemente con los locales. 
Estas tres micro-estructuras traducen modos de integración relacional de tipo bien diferente, ninguno de los cuales constituye un puente.

Tras los perfiles puros están las modalidades mixtas, tal vez más frecuentes que las precedentes. Todas ellas son micro-estructuras que implican puentes entre distintas meso-estructuras. Examinemos primero microestructuras "duales" que combinan dos de los tres tipos de relaciones y establecen por lo tanto un solo tipo de puente. La aquí llamada de extranjeros combina relaciones con personas de igual origen $u$ otros extranjeros presentes en el entorno, pero no tienen relaciones con los locales. El extranjero es un individuo que sigue manteniendo una distancia respecto a la sociedad de acogida (o que la sociedad de acogida sigue manteniendo a distancia), por lo tanto sin integrarse en esta, mucho menos asimilarse a esta. Esta micro-estructura constituye un puente entre la sociedad de origen y la comunidad transnacional, pero no con las mesoestructuras relacionales de la comunidad de acogida.

La integración llamada bi-local da cuenta de aquellos que tienen relaciones con personas de igual origen y con locales, pero que no tienen relaciones con un círculo de expatriados. Están ligados al mundo del que provienen, el que ha dado forma a sus normas de referencia originales, y a la sociedad de acogida, que estructura el contexto presente. Estos individuos tejen puentes directos entre los dos mundos sobre los que tienen más información, ligando las meso-estructuras relacionales de la sociedad de origen y la de acogida.

La figura del fugado corresponde a aquellos que evitan (o que no pueden tener) contacto con personas de su propia nacionalidad, pero que tienen contactos con personas de otros orígenes: otros extranjeros y locales. Esta micro-estructura relaciona las meso-estructuras transnacionales con las de la sociedad de acogida.

Finalmente un último perfil combina los tres tipos de lazos: nacionales, transnacionales y locales: se trata del cosmopolita, verdadero ciudadano del mundo capaz y deseoso de entrar en contacto con todo tipo de personas. No se limita a un mundo social, sino que es capaz de moverse con facilidad en los distintos medios sociales y de tener una red diversificada 
independientemente de los orígenes de sus asociados. Su micro-estructura de integración relacional establece de forma simultánea los tres puentes posibles, o si se prefiere, un puente múltiple, lugar de intersección cruzadas entre las meso-estructuras de la sociedad de origen, de acogida, así como las comunidades transnacionales en que participa.

Veamos a continuación un ejemplo para ilustrar el uso de esta tipología de micro-estructuras de integración relacional y de cómo permiten a la vez caracterizar los actores, los puentes que crean entre meso-estructuras diferentes y la combinatoria de los distintos tipos de micro-estructuras en distintos contextos.

\section{Un ejemplo de aplicación. Perfiles de integración relacional de estudiantes europeos móviles}

Ilustramos esta propuesta de tipología mediante un ejemplo concreto de migrantes Europeos de corta duración. Se trata de una muestra de estudiantes participantes en un programa de intercambio de estudiantes de la Unión Europea Sócrates-Erasmus. El programa Erasmus es el programa educativo estrella de la UE. Existente desde 1987, es el más antiguo de ellos y el que más recursos ha recibido (entorno a 460 millones de Euros en el periodo 1995-1999) ${ }^{[6]}$. Desde su creación ha permitido a un número creciente, hasta la fecha más de millón y medio, de estudiantes de toda Europa $^{[7]}$ pasar entre 3 y 12 meses en otra universidad europea con el reconocimiento de dicho periodo de estudio en su universidad de origen. Se puede considerar que los estudiantes Erasmus son los pioneros de lo que podría convertirse en el espacio universitario europeo tras la aplicación de los acuerdos de Bolonia y la creación de un espacio único europeo.

La muestra presentada aquí está compuesta de 242 estudiantes Erasmus procedentes de 22 países y que fueron acogidos en 1995 o 1999 en la Universidad Pública de Navarra (España), la Université des Sciences et Technologies de Lille (Francia) o la Rijkjse Universiteit Groningen (Holanda).

Distinguimos por lo tanto 4 sub-muestras según su contexto de movilidad: los estudiantes Erasmus acogidos en Lille en $1995(\mathrm{~N}=80)$, y en 1999 
( $N=77)$, aquellos en Pamplona en $1999(\mathrm{~N}=34)$ y en Groningen en 1999 $(\mathrm{N}=50)$.

En este contexto teóricamente pueden darse los 8 perfiles descritos anteriormente. Un estudiante Erasmus aislado no tiene ningún amigo con personas de ningún tipo. El Erasmus nacional tiene amigos sólo de su país y por lo tanto aprendería lo mínimo sobre las diferencias normativas entre su país y el país de acogida o los otros países europeos. Por otra parte este tipo de integración le permitiría mantener un modo de vida y un tipo de sociabilidad lo más parecido posible al que tendría en su país, o por lo menos vivir sus relaciones sociales según los modelos que ya conoce. Podría adoptar un modo de comportamiento de "vacaciones" o "transgresivo" o "en el extranjero" que no son los que utiliza habitualmente, pero que comparte con las personas de su propia nacionalidad. El hecho de tener amigos del propio país permite no tener que llegar a compromisos ni modificar ciertos comportamientos cotidianos (los españoles tenderán a cenar a las 10 de la noche, los finlandeses a las 5 de la tarde), o las formas típicas de sociabilidad y las normas sobre los comportamientos recíprocos. Por ejemplo, en caso de salir un sábado por la noche el hecho de tener amigos de misma nacionalidad aclara inmediatamente si es necesario emborracharse, flirtear con los desconocidos, o si por el contrario ignorar totalmente a las personas que no se conoce, si se pagan las consumiciones de todo el mundo por turnos o si cada uno paga lo suyo, si el estatus en el grupo depende de quien es capaz de beber más, de bailar mejor o durante más tiempo, de tener la pareja más vistosa...

El caso del apátrida correspondería en este caso con el de individuos que sólo tienen como amigos a otros estudiantes Erasmus. De alguna manera los otros Erasmus son, después de las personas de igual nacionalidad, aquellos que más se asemejan socialmente: ocupan la misma posición sociológica de extranjero (tal como la caracterizan Simmel 1908 o Schutz 1954) y tienen rasgos sociales y trayectorias biográficas parecidas (de Federico 2003). Se trata de un perfil empíricamente probable. El perfil de tránsfugo, aquel estudiante Erasmus que sólo tendría amigos del país de acogida, parece sin embargo poco probable, aunque en otros tipos de 
migrantes de más larga duración pueda darse, y especialmente en casos en que la migración ha sido voluntariamente individual.

Entre los perfiles "duales", aquel del extranjero constituye sin duda el de menor esfuerzo o menos capacidades relacionales para los estudiantes Erasmus (amigos del mismo país y otros extranjeros) aunque no sea necesariamente el perfil que tanto los estudiantes Erasmus como las universidades de acogida prefieran, ya que no implica ningún contacto con los locales. Es esperable que sea el más frecuente entre las modalidades duales. El Erasmus bi-local es aquel que desarrolló relaciones de amistad con personas de su país de origen y con estudiantes locales, pero que no ha entrado en contacto con personas de otros países. El fugado, probablemente el menos probable de los casos duales no tiene amigos de su país, sólo otros Erasmus y locales. Finalemente, el perfil cosmopolita es probablemente el más frecuente en el caso de los estudiantes Erasmus y hace referencia a personas que establecen relaciones de amistad con personas de su país, con otros Erasmus y con locales.

Veamos qué sucede con los estudiantes Erasmus de estos 4 contextos. Dado el número reducido de casos (4) no será posible interpretar el porqué de las diferencias entre las 4 sub-muestras, sin embargo servirán para darse cuenta del interés de dicha tipología para analizar y comparar los espacios sociales de la transnacionalidad en diferentes contextos.

De forma general vemos que la micro-estructura más frecuente es la de cosmopolita. ( $65 \%$ de los casos). A continuación las más frecuentes son las de extranjero (15\% sin relaciones locales) y de bi-local (13\% sin relaciones con otros Erasmus). Fugados (sin relaciones con nacionales), apátridas (sólo relaciones Erasmus) y nacionales (sólo relaciones nacionales) representan $8 \%$ de los casos respectivamente. Finalmente las microestructuras de aislados (sin amigos) y tránsfugos (sólo amigos locales) son prácticamente inexistentes.

Tabla 4. Micro-estructuras relacionales en los 4 contextos.

\begin{tabular}{|l|c|c|c|c|c|c|c|c|c|c|}
\hline Micro-estructuras & \multicolumn{2}{|c|}{ Lille 95 } & \multicolumn{2}{|c|}{ Lille 99 } & \multicolumn{2}{c|}{ Pamplona 99 } & Groningen 99 & \multicolumn{2}{c|}{ Total } \\
\hline Perfil & № & $\%$ & № & $\%$ & № & $\%$ & № & $\%$ & Nb. & $\%$ \\
\hline
\end{tabular}




\begin{tabular}{|l|c|c|c|c|c|c|c|c|c|c|} 
Aislado & 0 & $0 \%$ & 0 & $0 \%$ & 1 & $3 \%$ & 0 & $0 \%$ & 1 & $1 \%$ \\
\hline Nacional & 2 & $3 \%$ & 11 & $19 \%$ & 0 & $0 \%$ & 2 & $4 \%$ & 15 & $8 \%$ \\
\hline Apátrida & 3 & $4 \%$ & 1 & $2 \%$ & 2 & $6 \%$ & 8 & $17 \%$ & 14 & $8 \%$ \\
\hline Tránsfugo & 1 & $1 \%$ & 0 & $0 \%$ & 0 & $0 \%$ & 0 & $0 \%$ & 1 & $1 \%$ \\
\hline Extranjero & 1 & $1 \%$ & 15 & $26 \%$ & 4 & $12 \%$ & 8 & $17 \%$ & 28 & $15 \%$ \\
\hline Bi-local & 19 & $24 \%$ & 4 & $7 \%$ & 1 & $3 \%$ & 0 & $0 \%$ & 24 & $13 \%$ \\
\hline Fugado & 2 & $3 \%$ & 0 & $0 \%$ & 5 & $15 \%$ & 8 & $17 \%$ & 15 & $8 \%$ \\
\hline Cosmopolita & 51 & $65 \%$ & 26 & $46 \%$ & 21 & $62 \%$ & 22 & $46 \%$ & 120 & $65 \%$ \\
\hline Total & 79 & $100 \%$ & 57 & $100 \%$ & 34 & $100 \%$ & 48 & $100 \%$ & 184 & $100 \%$ \\
\hline Valor perdido & 1 & $1 \%$ & 20 & $26 \%$ & 0 & $0 \%$ & 2 & $4 \%$ & 23 & $11 \%$ \\
\hline
\end{tabular}

Esta especificación de los tipos posibles de micro-estructuras, o estructuras elementales de la integración relacional de los migrantes ha permitido caracterizar a los actores y sus modalidades de integración. Ahora bien, más interesante todavía es ver cómo esta tipología permite al mismo tiempo, mediante el examen de su combinatoria en un espacio social definido caracterizar los diferentes contextos (localidades o comunidades transnacionales). De hecho los puentes tendidos por las diferentes microestructuras devienen propiedades definitorias de los espacios sociales de la transnacionalidad en los distintos contextos sociales al dar cuenta de las diferentes modalidades de intersección e interdependencia de las mesoestructuras relacionales.

Así pues podemos constatar diferencias entre los diferentes contextos. En Lille 95 las micro estructuras dominantes son la cosmopolita (65\%) y la bilocal (24\%), lo que sugiere que los espacios sociales de la transnacionalidad están repartidos en este contexto entre un círculo propiamente transnacional en que la mayor parte de los migrantes participa al mismo tiempo que mantiene relaciones tanto localmente como con la comunidad de origen tejiendo puentes múltiples entre las tres comunidades. Otros, sin embargo, no participan del círculo transnacional y reparten su tiempo entre contactos locales y personas originales de sus países constituyendo puentes exclusivamente entre la sociedad de origen y la de acogida.

En Lille 99 las micro-estructuras de integración relacional más frecuentes son las de cosmopolita $(46 \%)$, extranjero ( $26 \%$ sin relaciones locales) y 
nacionales (19\% sin relaciones locales ni con otros Erasmus). En este caso encontramos que los espacios de la transnacionalidad han cambiado respecto al 95. Seguimos encontrando un gran conjunto de cosmopolitas, aproximadamente la mitad de individuos, que participan en el círculo propiamente transnacional al mismo tiempo que siguen conectados tanto localmente como con sus comunidades de origen y que por lo tanto interconecta las tres comunidades. Sin embargo un cuarto participa en el círculo transnacional y mantiene relaciones con sus orígenes, sirviendo de puente entre estas comunidades, , pero no ha logrado en absoluto trabar relaciones con locales. Asimismo, cerca de uno de cada cinco está encerrado solamente en su comunidad de origen y no establece por lo tanto ningún puente. El espacio social de la transnacionalidad de Lille 99 está mucho más desligado en su conjunto de las meso-estructuras locales que Lille 95.

En Pamplona 99, encontramos también cosmopolitas (62\%) y extranjeros ( $12 \%$ sin relaciones locales), aunque en este caso la parte de cosmopolitas es mayor en detrimento de los extranjeros. Por otro lado la tercera microestructura presente es la de fugados (17\% sin relaciones con nacionales), que establecen puentes entre la comunidad transnacional y la de acogida. Este caso contrasta por lo tanto fuertemente con el anterior en la medida en que los espacios de la transnacionalidad están mucho más ligados a las meso-estructuras de la comunidad de acogida.

En el último contexto, Groningen 99 las micro estructuras son más variadas $y$, aunque seguimos encontrando casi la mitad de cosmopolitas (46\%), extranjeros ( $\sin$ relaciones locales), fugados (sin relaciones con nacionales) y apátridas (sólo relaciones Erasmus), representan respectivamente a casi uno de cada cinco encuestados (17\%). Así pues las micro-estructuras están bastante diversificadas en esta localidad. Una mayoría de cosmopolitas teje, como en los 2 contextos precedentes, puentes múltiples entre las tres comunidades de origen, transnacional y de acogida. Los extranjeros establecen puentes entre la comunidad de origen y la transnacional. Los fugados, más originales, tejen puentes entre la comunidad transnacional y la local. Finalmente los apátridas no tejen puentes y se sumergen 
exclusivamente en la comunidad transnacional. Las interdependencias entre las comunidades son por lo tanto más complejas en este contexto.

Gracias a la distribución de las micro-estructuras podemos constatar en la ilustración propuesta las similitudes y diferencias fundamentales entre estos cuatro contextos. Los cuatro se parecen en cuanto a que en ellos emergen círculos cosmopolitas propiamente transnacionales que conciernen a la mayoría de los individuos. Podemos por lo tanto hablar de la aparición de meso-estructuras propiamente transnacionales en estos contextos. Por otra parte, los 4 contextos difieren en cuanto al anclaje local de dichas comunidades transnacionales y en su relación respecto a las comunidades de origen. Además, observamos que ciertos contextos presentan estructuras de interdependencia más complejos y diversificados que otros.

Hemos demostrado la utilidad del uso de la tipología de micro-estructuras para caracterizar los espacios sociales de transnacionalidad de distintas comunidades más allá de lo que hubiera permitido una mera tabla de frecuencias de los tipos de lazos hallados en cada una de ellas ya que distribuciones iguales de tipos de lazos pueden hacer referencia a tipos de micro-estructuras diferentes con más o menos puentes entre las distintas meso-estructuras.

\section{Conclusión}

En este artículo hemos propuesto una tipología de los modos de integración relacional de los migrantes a partir de una triple distinción entre lazos locales, nacionales y transnacionales. Se han identificado distintos perfiles de integración mediante la definición ocho micro-estructuras relacionales (aislado, nacional, apátrida, tránsfugo, extranjero, bi-local, fugado o cosmopolita) resultantes de la combinatoria de lazos con personas de la sociedad de acogida, de la sociedad de origen y otros migrantes. Estas micro-estructuras incluyen (o no) diferentes tipos de puentes entre las meso-estructuras relacionales.

Esta caracterización de los tipos posibles de micro-estructuras, o estructuras elementales de la integración relacional permiten simultáneamente caracterizar a los actores y sus modalidades de 
integración y, mediante la combinatoria de micro-estructuras presente en un espacio social definido, los diferentes tipos de comunidades de migrantes, su calidad transnacional, su relación con la sociedad de acogida. La cuestión clave es que éstas distribuciones dan información no sólo sobre las comunidades en sí mismas, sino sobre las maneras en que éstas unidades efectúan la intersección con sistemas relacionales no locales ilimitados hablándonos de los diferentes espacios sociales de la transnacionalidad.

La tipología propuesta representa varias ventajas respecto a las de Ferrand (2002) y Berry (1986). La ventaja principal respecto a propuesta de Berry es que este último considera la adaptación de los migrantes solamente teniendo en cuenta las relaciones a las comunidades de origen y de acogida, olvidando los aspectos propiamente transnacionales que pueden darse en los procesos migratorios. La tipología propuesta en este artículo permite por lo tanto una mayor capacidad descriptiva de los tipos de integración posibles. En comparación con la tipología de Ferrand, la propuesta aquí también permite una mayor capacidad descriptiva para el caso de los migrantes al considerar, en lugar de dos tipos de relaciones (locales/no locales), tres lazos distintos (nacionales, transnacionales, locales). La tipología propuesta aquí tiene una ventaja adicional y es la adopción del punto de vista de la comunidad que se pretende estudiar () en lugar de un punto de vista necesariamente geográfico ligado a una localidad. Esto añade versatilidad al instrumento de observación. Se trata por lo tanto de un instrumento, además de sencillo, multifacético y versátil, ya que en principio sirve para caracterizar 1 ) elementos diferentes, ya que permite a la vez caracterizar los actores, los puentes que crean entre mesoestructuras diferentes y la combinatoria de los distintos tipos de microestructuras en distintos contextos 2) los espacios sociales de la transnacionalidad en diferentes contextos sociales, ya sean estos comunidades de inmigrantes de igual origen, comunidades transnacionales, comunidades nacionales trans-estatales, localidades $\mathrm{u}$ otros contextos sociales cuyas meso-estructuras transnacionales se pretendan estudiar. Esta tipología puede ser aplicada tanto si se tiene acceso a la totalidad de la 
población, como si se está limitado a proceder mediante muestras aleatorias.

En el caso estudiado las cuatro sub-muestras estudiadas se parecen bastante -todas presentan una mayoría de cosmopolitas- sin duda dado que en los cuatro casos se trata del mismo tipo de población -jóvenes europeos realizando una movilidad de corta duración- en un contexto institucional parecido -universidades en que su presencia está programada y sus estudios reconocidos. A pesar de eso la descripción de las micro-estructuras deja entrever diferencias significativas sobre las distintas intersecciones de las meso-estructuras en los 4 contextos. Sería importante aplicar esta tipología a otros tipos de comunidades de migrantes para constatar su capacidad y su pertinencia descriptiva.

Por otra parte sería interesante explorar en el futuro dos sofisticaciones posibles de la tipología. En primer lugar sería importante explorar la pertinencia cuantitativa en la construcción de la tipología además de las distinciones cualitativas aquí propuestas. La tipología aquí presentada se ha construido a partir de la presencia o ausencia de los distintos tipos de lazos (nacionales, transnacionales, locales), la cantidad de cada tipo de lazo puede ser una consideración importante dada la dificultad diferencial de acceso a tales lazos - en la población estudiada los lazos locales son mucho menos frecuentes que los demás- y dado que distintos tipos de lazos pueden dar acceso diferencial a distintos tipos de recursos. Un premier paso puede ser hablar de "dominantes" en los distintos perfiles, esto es, el tipo de lazo más abundante en la micro-estructura. Por ejemplo se pueden dar cosmopolitas de dominante local o de dominante nacional, extranjeros de dominante transnacional y así sucesivamente. Puede ser interesante también explorar especificaciones a partir de datos empíricos que vayan más allá de la descripción del lazo dominante de la micro-estructura y que tengan en cuenta el número. Sin embargo la especificación en este sentido no debiera multiplicar el número de categorías más allá de lo inteligible para la tipología.

Una segunda sofisticación de la tipología o del estudio de esta sería tener en cuenta la dimensión temporal de los procesos migratorios. La dimensión 
temporal tiene importancia de dos maneras a nivel individual, por una parte respecto a la supuesta duración total de la migración. No es lo mismo una migración de unos meses, un año, varios años, sin fecha de regreso conocida o sin regreso. Distintas temporalidades migratorias pueden favorecer modalidades de integración diferentes. Por otra parte la dimensión temporal es importante en lo que respecta al propio proceso migratorio. Para un individuo dado, las modalidades de integración pueden variar según si se trata del momento próximo al de llegada a la localidad de acogida o si ya lleva mucho tiempo en esta. Sería interesante estudiar las variaciones en las modalidades de integración de los individuos y de constatar si existen periodos particulares asociados a ciertas categorías y/o momentos de estabilización en un cierto tipo de categoría. A nivel colectivo la dimensión temporal es interesante para constatar la volatilidad, la permanencia, la sustitución, de los distintos tipos de puentes entre comunidades, por lo tanto la evolución de las interdependencias entre meso-estructuras relacionales.

Otras dos líneas de investigación merecen ser profundizadas a partir de la tipología propuesta. Primeramente se plantea la cuestión de a qué se debe que en diferentes contextos aparezcan diferentes micro-estructuras. Tomadas de forma individual, las diferencias de perfiles de integración relacional podrían ser entendidas como la consecuencia de distintas preferencias individuales de integración, pero cuando se examina la agregación de estas micro-estructuras y se constatan las diferencias de combinatorias presentes en diferentes contextos es importante preguntarse en qué medida éstas se deben a presiones propiamente contextuales. En otras palabras es posible tomar la presencia de diferentes combinatorias de micro-estructuras en un contexto dado como una variable dependiente a explicar a partir de características individuales: preferencias personales (p.e. introversión o extroversión, preferencia por cierto tipo de integración) y características socio-demograficas (p.e. sexo, edad, estatus...), pero también a partir de características contextuales: variables institucionales (p.e. las políticas públicas respecto a la inmigración y las diferentes comunidades de migrantes) y variables de composición (p.e. la presencia de inmigrantes de diferentes orígenes). 
En segundo lugar, también es interesante estudiar las consecuencias de las diferentes micro-estructuras tanto en el devenir individual como el colectivo. Las diferentes micro-estructuras dan cuenta de accesos diferenciales a formas de capital social diferente al igual que a mundos culturales y normativos distintos. Sería interesante examinar cómo las diferentes micro-estructuras tienen efectos en el acceso a los recursos que permiten la inserción laboral, la influencia política (local o en la sociedad de origen), la salud... Pero también sus incidencias en la circulación de la información, la difusión de ideas y la innovación transnacional, incluyendo la hibridación cultural y la interculturación.

\section{Bibliografía}

Abélès, M. (1998). Hommo Communautarius. Quelle Identité pour l'Europe ?. Le multiculturalisme à l'epreuve, 43-63. Presses de la Fondation Nationale del Scienes Politiques. Paris.

Albrow, M. (1990) «Introduction » in M. Albrow y E. Kings (eds.) Globalization, Knowledge and Society. London. Sage.

Amersfoort, H. y Doomernij, J. (1999) «Modern Diaspora's: Transnationalism and Immigrant Communities: The Case of Turkish Immigrants in Western Europe. » Presentado en la Conferencia Internacional Globalization and Identities, 30-junio a 2-julio 1999. Manchester Metropolitan University.

Barnes J.A. (1954). Class and comittees in a Norwegian Island parish. Human Relations, 7:9-58.

Belorgey, J.M. (1989/2000). Transfuges. Éditions Autrement. Paris.

Berry, J.W. (1986). «The acculturation process and refugee behavior». In Williams, C.L. et Westermeyer, J. (eds.) : Refugee mental health in resettlement countries. The series in clinical and community Psychology : 25-27. Hemisphere Publishing Corporation. Washington.

Bunt, G.G. van de (1999). Friends by choice. Thesis Publishers ICS series. Amsterdam.

Cresson G. Ferrand A. Lardé P. Les systèmes locaux de santé Programme CNRS «Santé Société », Lille CNRS Clersé, 2001 
de Federico de la Rúa, A. (2003). Redes de identificación con Europa. Amistad e identidades de estudiantes europeos. Tesis co-tutelada bajo la dirección de Alexis Ferrand (Universidad de Lille) y Mercedes Pardo (UPNA).

Favell, A. (1999). «Is transnational social capital possible? Comparing elite and ethnic migrants in Brussels ». ESFECSR Conference European society or European societies? Migrations and inter-ethnic relations in Europe: 23-28 Septiembre, Obernai, France.

Ferrand, A. (1997). «La structure des systèmes de relations » L'Année Sociologique 1997, 47(1) :37-54.

Ferrand, A. (2002). « Las comunidades locales como estructuras meso ». REDES. Revista hispana para el análisis de redes sociales, 4, 2002.

Ferrand, A. Mounier, L. (1999) «The diversity of personal networks in France ; social stratification and relational structures » in Wellman B. (ed.) Networks in the Global Village, Boulder, Westview Press, 185-224.

Fischer C.S. (1982). To Dwell Among Friends: Personal Network In Town And City. University Press. Chicago.

Giddens, A. (1998) The Third Way: The Renewal of Social Democracy. Polity Press.

Gordon, M.M. (1964). Asimilation in American Life. Oxford University Press. New York.

Kennedy, P. «Introduction» Conferencia Networks And Transformations organizada por la Global Studies Association, Manchester Metropolitan University, Manchester, UK, 2-4 julio, 2001.

Kohli, M. (2000). «The battlegrounds of European Identity ». European Societies 2000, 2(2) : 113-137.

Lin, N. (2001) Social capital: a theory of social structure and action. Cambridge University Press.

Merton, R.K. (1965). «Types d'influence: local ou cosmopolite ». In Éléments de théorie et de méthode sociologique. Plon. Paris.

Pourmedhi, M. «Emerging Transnationalism amongst Iranian Exiles in Manchester » paper presentado en la Conferencia Networks And Transformations organizada por la Global Studies Association, Manchester Metropolitan University, Manchester, UK, 2-4 julio, 2001. 
Recchi, E. et Nebe, T. (2003). «Migration and political identity in the European

Union : Research issues and theoretical premises ». Pioneur, Working Paper No. 1, Julio 2003.

Redfield, R. ; Linton, R. et Herskovits, M. (1936). « Memorandum on the study of acculturation ». American Anthropologist,38, 149-152.

Schütz, A. (1944/1974). «El forastero. Ensayo de psicología social». Estudios sobre teoría social: 95-107. Amorrortu. Buenos Aires.

Schütz, A. (1944/1974). «La vuelta al hogar ». Estudios sobre teoría social : 108119. Amorrortu. Buenos Aires.

Simmel, G. (1908/1992). Sociologie. Presses Universitaires de France.

Teichler, U. ; Gordon, J. et Maiworm, F. (2001), Socrates 2000 Evaluation Study. Nov. 2000. Contract № 1999-0979/001-001 SOC 335 BEV. Étude pour la Comission Européenne.

Wagner, A.C. (1998). Les nouvelles élites de la mondialisation . PUF.

Wellman B. (1979) «The community question : The intimate networks of east Yorkers ». American J ournal of Sociology, 84(5).

Wellman B. Berkowitz S.D. (1988) (eds.) Social Structures. A Network Approach. Cambridge, Cambridge University Press.

Wellman, B. (1982) «Studying personal communities ». Marsden P. Lin N. (eds.), Social Structure And Network Analysis, Beverly Hills, Sage.

\footnotetext{
[1] Agradezco a Alexis Ferrand la inspiración constante que supone trabajar con él. Gracias también a Victor Hugo Bogarín, a Isidro Maya Jariego y a José Luis Molina por sus útiles comentarios a versiones anteriores de este texto.

[2] Envíese la correspondencia a Ainhoa de Federico: federico@univ-lillel.fr

[3] Toda construcción de tipologías implica una reducción o selección de los rasgos considerados más pertinentes en detrimento de otros. Se podrían realizar diferentes matizaciones para volver esta tipología más fina y al mismo tiempo más compleja, por ejemplo, se podría distinguir entre las relaciones con personas de la sociedad de origen que se encuentran en la sociedad de origen, las que se encuentran en la sociedad de origen y las que se encuentran en otra parte (para un español en Francia, amigos españoles en España, españoles en Francia, o amigos españoles en Alemania). Evidentemente se puede hacer otro tanto con las personas de la sociedad de acogida y las de otros orígenes. Estas matizaciones tienen sentido del punto de vista del capital social que constituyen y de los recursos diferenciales a los que dan acceso, no tanto de un punto de vista cultural y normativo. Una segunda puntualización es que la cuestión de las fronteras pertinentes de los “orígenes" puede variar. En Europa, el continente más nacionalizado, la referencia al país de origen puede ser la más pertinente. Sin embargo tal vez latinoamericanos y árabes se reconozcan un "origen" común pese a venir de países diferentes. Una última puntualización es que la tipología presentada aquí es una tipología meramente cualitativa. No nos dice nada sobre la cantidad de lazos de cada tipo, tampoco de la "dominante" del tipo
} 
de lazo, esto es, el tipo de lazo más abundante en la micro-estructura. Por ejemplo se pueden dar cosmopolitas de dominante local o de dominante nacional, extranjeros de dominante transnacional y así sucesivamente. Evidentemente al construir la tipología es necesario un compromiso entre la precisión y la generalidad aprehensible útiles al objeto de investigación.

[4] En la literatura sobre las migraciones es habitual emplear el término de "comunidad transnacional" para referirse a individuos de una misma procedencia geográfica pero dispersos territorialmente que, pese a todo, conforman una comunidad en lo relacional. Por ejemplo, familias marroquíes que vivan a caballo de Marruecos, España, Bélgica y Francia. Siguiendo las distinciones de la literatura sobre la nación y el estado, sería más correcto llamar el citado ejemplo una comunidad nacional transestatal. En ese caso, se reservaría el término de "comunidad transnacional" a aquella comunidad que agrupa o relaciona personas de nacionalidades diferentes independientemente de en qué estado se encuentren. Ese es el sentido que se le da en este artículo.

[5] Tal vez pudiésemos hablar aquí de "puente aislado" o "puente circunscrito" que indica la ausencia de puente estructural y la presencia de un contacto entre personas de origen distinto.

[6] Ver la evaluación Sócrates 2000 de Teichler et al. (2001).

[7] Participan en el programa Sócrates-Erasmus todos los países de la antigua EU a 15: Alemania, Austria, Bélgica, Dinamarca, España, Francia, Finlandia, Gran Bretaña, Grecia, Holanda, Irlanda, Italia, Luxemburgo, Portugal, Suecia; una buena parte de los nuevos miembros y candidatos: Chipre, Rumanía, Hungría, Polonia, República Checa, Eslovaquia, Bulgaria, Eslovenia, Estonia, Letonia, Lituania; así como Islandia, Liechtechtein, Noruega y Suiza. 